\title{
Celso Furtado na busca da melhor "estrutura" para compreender e propor o Desenvolvimento Latino-americano
}

Adriano de Amarante*

\section{Resumo}

Neste ensaio, expõe-se o modo de pensar e as principais noções apresentadas na produção literária de Celso Furtado sobre o Desenvolvimento Socioeconômico. Neste estudo exploratório-qualitativo, faz-se um resgate bibliográfico no tocante a obra de Furtado na tentativa de sistematizar e apresentar as principais ideias sobre o Desenvolvimento Econômico e Social. O principal resultado desta revisão experimental foi apresentar que as ideias e definições resgatadas dos textos de Furtado permanecem atuais e ainda presentes em nossa sociedade, a estrutura econômica e social desigual, a presença de um sistema capitalista dual em que convivem o subemprego em atividades informais e o trabalho formal e altamente qualificado e um sistema cultural com vícios de uma sociedade arcaica. $\mathrm{O}$ texto foi estruturado em 6 seções incluindo as considerações finais.

Palavras-chave: Celso Furtado; Subdesenvolvimento; Progresso Técnico; Cultura;

\section{Celso Furtado in search of the best "structure" to understand and propose Latin American Development}

\begin{abstract}
In this essay, the way of thinking and the main notions presented in Celso Furtado's literary production on Socioeconomic Development are exposed. In this exploratory-qualitative study, a bibliographic review regarding Furtado's work is done in an attempt to systematize and present the main ideas about Economic and Social Development. The main result of this experimental review was showing that the ideas and definitions recovered from Furtado's texts remain actual and still present in our society, the unequal social economic structure, the presence of a dual capitalist system, in which underemployment coexists with formal activities of highly qualified labor force and a cultural system with the addictions of an archaic society. The text was structured in 6 sections including the final considerations.
\end{abstract}

Keywords: Celso Furtado; Underdevelopment; Technical Progress; Culture;

Código JEL: O10; O21; O54

\footnotetext{
* Professor do Departamento de Ciências Econômicas da Universidade do Estado de Santa Catarina (UDESC). E-mail: adriano.amarante@udesc.br
} 


\section{Introdução}

Sem dúvidas, um estudioso dedicado aos problemas econômicos e sociais latinoamericanos. Justamente pela busca incansável por soluções concretas às mazelas do subdesenvolvimento, Celso Furtado mergulhou em mares teóricos das mais diversas abordagens. Sem preconceitos e com objetivo claro, cada linha de pensamento pode ser uma peça útil para uma proposta clara e articulada na construção de uma sociedade Brasileira e Latino-Americana continuamente menos desigual e mais prospera.

Em seu pensamento, o fenômeno econômico e social é explicado não somente por meio de modelos econômicos analíticos, mas deve recorrer ao estudo do movimento histórico das relações e estruturas sociais, ${ }^{1}$ apesar da complexidade de seu modo de pensar, suas obras são tecnicamente rigorosas e facilmente compreendidas e por consequência, referenciadas por inúmeros estudiosos, sejam eles críticos ou seguidores de seu pensamento. Em sua introdução à Formação Econômica do Brasil, Furtado com elevado grau de preciosismo, evidencia a sua preocupação sincera com os leitores: "sem uma adequada profundidade de perspectiva torna-se impossível captar as inter-relações e as cadeias de causalidade que constituem a urdidura dos processos econômicos" (FURTADO, 1961, p. 9).

No prefácio da 32ª edição de Formação Econômica do Brasil, Plínio de Arruda Sampaio Jr. deixa claro as pretensões do autor ao citar Max Weber em "a vida pode ser racionalizada de acordo com perspectivas e direções extremamente diferentes" e ao concluir indica que a visão de Brasil para Celso Furtado não se resume a "escolha binaria entre o modernismo acelerado dos neoliberais ou a nostalgia extemporânea dos nostálgicos neodesenvolvimentistas" (SAMPAIO, 2005, p. 8).

Celso Furtado foi fortemente influenciado por Raul Prebisch ${ }^{2}$, fundador da escola estruturalista aplicada a problemas econômicos latino americanos, tendo Celso contribuído e chegando a ter o conjunto de sua obra definido como "Economia Política do Desenvolvimento Latino-americano"3, por importantes pesquisadores.

\footnotetext{
${ }^{1}$ Na preparação do manuscrito Formação Econômica do Brasil, Furtado (1961, p. 9) sugere que "a assimilação das teorias econômicas requer mais e mais ser completada, ao nível universitário, pela aplicação dessas teorias aos processos históricos subjacentes à realidade na qual vive o estudante e sobre a qual possivelmente terá de atuar", assumindo que sua obra tem caráter introdutório as ciências econômicas e sociais.

${ }^{2}$ Prebisch (1951) trata-se de um trabalho que sintetiza sua teoria e várias de suas suposições e argumentos teóricos podem ser identificados nos trabalhos de Furtado.

${ }^{3}$ Autores como Szmrecsányi (2005), Bresser-Pereira (2004), Bielschowsky (2006) e Boianovisky (2012), apesar das referências se direcionarem a principal economia da América Latina, a brasileira. Certamente existem contribuições em outras áreas, mas aqui o interesse se limita a teoria do desenvolvimento sócio econômico.
} 
A proposta deste ensaio é discutir sua astúcia na maneira de pensar e discutir o Desenvolvimento Socioeconômico dos países Latino-americanos ${ }^{4}$ com destaque às dimensões estruturais social e econômica.

E, esse manuscrito está estruturado em 6 seções. Nessa primeira seção, apresenta-se o propósito do texto. $\mathrm{Na}$ segunda seção, faz-se uma breve discussão sobre as metodologias utilizadas por Furtado na análise dos fenômenos econômicos e na fundamentação de projetos e planos de desenvolvimento; aqui, não se pretende fazer uma discussão profundada sobre o método, mas compreender como ele explica o subdesenvolvimento. Na terceira seção, discutese como o sistema cultural afeta a estrutura econômica e social. Na quarta seção, apresenta-se uma breve discussão sobre a estrutura heterogênea do subdesenvolvimento. Na quinta seção, apontam-se os condicionantes e ideias importantes para a compreensão do subdesenvolvimento, bem como suas políticas. Por fim, na sexta seção mostram-se algumas considerações finais sobre a problemática do subdesenvolvimento em nossa sociedade.

\section{Como explicar o subdesenvolvimento ${ }^{5}$}

Na Dialética do Desenvolvimento, Furtado (1964) deixa claro, a dificuldade de compreender os problemas econômicos e sociais das economias Latino Americanas. Ele discute as implicações do desenvolvimento econômico sobre o processo de mudança cultural e viceversa. Destaca que apesar do caráter "ahistórico" da teoria econômica moderna, os instrumentos metodológicos foram aperfeiçoados em modelos de equilíbrio parcial e geral, contudo tendo a permanência de dificuldades na análise dos problemas complexos ${ }^{6}$ de desenvolvimento econômico. O desenvolvimento, para ele, é um processo amplo de mudança social e para o compreender se faz necessário contextualizar historicamente o todo social e seu comportamento ao longo do tempo. A análise econômica histórica pode ser resgatada em autores da escola clássica (Adam Smith e David Ricardo) e por Marx que sugere uma "teoria da mudança social" aplicável ao estudo do desenvolvimento econômico na sociedade capitalista moderna. Um ponto crítico à concepção Marxista, destacado por Furtado, seria a tomada de juízos de valor

\footnotetext{
${ }^{4}$ Delfim Netto (1966) declara que o modelo apresentado por Celso Furtado na The Indian Journal of Economics em 1958, foi contribuição relevante ao estudo e compreensão do processo de desenvolvimento em economias abertas.

${ }^{5}$ No trabalho de Bresser-Pereira (2004) pode-se compreender com detalhe o(s) método(s) aplicados por Furtado em seus inúmeros trabalhos; nesta seção, busco entender os procedimentos metodológicos utilizados na compreensão da ideia de subdesenvolvimento.

${ }^{6}$ Aqui insiro o termo complexo para manter o argumento atual, já que a Teoria Moderna a que se refere evoluiu ao ponto de tratar de vários aspectos do desenvolvimento econômico ao longo das possíveis trajetórias de produtividade e desigualdade econômica. O termo complexo motiva a importância da análise histórica das estruturas e relações sociais que mudam, mas também influenciam no desenvolvimento econômico.
} 
ao progresso social, assumindo que o capitalismo necessariamente seria superado. ${ }^{7}$ Furtado ao juntar os estudos sobre mudança social no campo da antropologia e a sintetize das duas análises da economia, ao que se pode dizer um "progresso intelectual", numa melhor compreensão do desenvolvimento socioeconômico discorre:

\footnotetext{
"A introdução de modelos analíticos dinâmicos no estudo dos sistemas sociais representaria, por outro lado, para a antropologia e a sociologia o reencontro necessário com a teoria econômica. E para economia esse reencontro significou a volta a formas de pensamento historicistas" (FURTADO, 1964, p. 24).
}

Neste caso, coube aos antropólogos estudar as causas fundamentais das mudanças culturais, recobrando o interesse histórico na análise da interação entre elementos materiais e não materiais do sistema cultural de uma sociedade.

Em Furtado (1979, p. 81) ele sugere a utilização do método lógico-dedutivo quando explica que a análise econômica de certos fenômenos pode ser simplificada por modelos estruturados com variáveis e equações. Furtado (1979, p. 268) define modelo como “... um conjunto coerente de relações entre dados possíveis de expressão quantitativa, capaz de explicar o funcionamento de uma unidade econômica simples ou complexa". Mas argumenta que o estudo rigoroso da economia requer uma dupla abordagem, nesse momento menciona a importância de adicionar ao estudo da análise econômica, o enfoque histórico para compreensão das da dinâmica das relações sociais. (FURTADO, 1979, p. 85-6).

Furtado (1979, p. 732-74) deixa claro que necessita desses dois enfoques para elaborar a análise e propostas de políticas para o desenvolvimento, em que a estrutura diversificada das economias desenvolvidas possibilita ao tomador de decisão atingir com "relativa eficácia" quanto ao objetivo da política econômica sem preocupações de cunho qualitativo. A "política qualitativa" pode ser entendida como instrumentos de índole social que provocam mudanças na estrutura de valores, para isso é necessário um estudo de abordagem histórico-cultural. Já a "política quantitativa", também importante, pode não funcionar dissociada de uma visão histórica das relações sociais e seus elementos culturais.

\section{Sistema cultural e estrutura econômica e social}

Como apresentado na seção anterior, para compreender a estrutura subdesenvolvida, se faz necessário entender como está estruturado o conjunto de elementos culturais dentro da

\footnotetext{
${ }^{7}$ Bresser-Pereira (2004) aponta para uma posição crítica de Furtado à ideia Marxista de colocar o Estado a serviço da burguesia ao suprimir direitos dos trabalhadores.
} 
sociedade subdesenvolvida e qual a dinâmica de funcionamento desta estrutura. De modo breve, pode-se definir o que são elementos materiais e não materiais da cultura, no primeiro temos a tecnologia, insumos e bens e serviços, no segundo estão os valores e costumes, a religião e formas de organização social.

As mudanças sociais e econômicas podem ser explicadas pela introdução de inovações originadas dentro do próprio sistema cultural, por isso uma mudança endógena, ou importada de outras culturas, nesse caso, exógena. A introdução de inovações tende a afetar um conjunto de valores anteriormente em equilíbrio, provocando uma mudança em todo o sistema formado por elementos culturais materiais e não materiais. Celso aponta que mudanças que partem da cultura material como inovações tecnológicas são de caráter dinâmico, e afetam toda a cadeia de valores. Essas mudanças provocam alterações na organização da produção, na distribuição do produto social que afeta "o processo social de formação do poder" com reflexos na política econômica implicando em mudanças em todas as engrenagens da economia e alteração na estrutura social. Em última instância, as inovações tecnológicas condicionam o processo de mudança social. No entanto, as mudanças no conjunto cultural não material se dão de forma mais lenta.

Em economias subdesenvolvidas, as mudanças rápidas com importação de novas tecnologias podem ter repercussões em todo conjunto de valores culturais não materiais (atitudes e hábitos), com uma revisão de expectativas e modificações em toda estrutura social. Contudo, nestas economias as reações em cadeia, ditas de grupos de interesse, tendem a regredir ao modelo antigo de desenvolvimento.

Furtado (1964) define o "desenvolvimento como um processo de mudança social pelo qual um número crescente de necessidades humanas - preexistentes ou criadas pela própria mudança - são satisfeitas através de uma diferenciação no sistema produtivo decorrente da introdução de inovações tecnológicas”. Neste sentido, quando há a introdução de uma inovação na cultura de uma sociedade, alguns grupos de interesse ficarão insatisfeitos, pois certos valores serão excluídos do sistema de elementos culturais e outros valores surgirão. Essa é uma busca consciente com valores que se excluem, o que possibilita o surgimento de conflitos sociais. As inovações afetam a superestrutura de valores, podendo causar conflitos entre grupos de uma classe dominante, pois provoca realocação de renda e um desequilíbrio de poder entre esses grupos.

Assim, quando do surgimento da inovação tecnológica e consequente aumento da produtividade, cria-se um excedente social que pode ser utilizado para aumentar a capacidade produtiva e ou para melhoria presente do bem-estar coletivo. Essa possibilidade de acumulação 
de capital só se viabiliza mediante uma sociedade de classes antagônicas, distante de uma sociedade com base na propriedade coletiva ${ }^{8}$, em que parte do excedente pode ser destinado à ampliação da capacidade produtiva, enquanto a classe trabalhadora se beneficia de outra parte (FURTADO, 1964, p. 28).

Bresser-Pereira (2004) usa o termo "dependência cultural" como um condicionante ao subdesenvolvimentismo. O caráter cultural do subdesenvolvimento faz com que ocorra um uso discricionário do excedente, originado do progresso técnico ou de outros fatores de mudança de produtividade, em direção ao consumo, em detrimento da acumulação de capital.

Logo, como conclui Furtado (1964, p. 28), essa divisão de classes é uma condição necessária para formação de capital e serve de "base para o processo histórico de desenvolvimento econômico", o que proporcionou um longo período de rápida melhoria no padrão de vida das economias capitalistas. Nesse se faz necessário admitir uma certa sincronia, entre "separação" das classes em estratos com a consciência coletiva de cada classe.

Uma ideia importante assinalada por Celso Furtado é a de que as inovações tecnológicas não apenas provocam mudanças no sistema produtivo, mas encadeiam um conjunto de mudanças nos elementos básicos de uma cultura, alterando toda uma estrutura social submetida a condicionantes históricos. Assim, ele passa a desvendar o porquê da trajetória de economias subdesenvolvidas divergir dos caminhos bem sucedidos das economias capitalistas desenvolvidas.

\section{Estruturas do subdesenvolvimento}

Furtado propõe como condição inicial para o subdesenvolvimento, uma heterogeneidade estrutural da economia e que é intensificada por fatores tecnológicos que tornam a estrutura econômica perene e o processo de subdesenvolvimento passa a se retroalimentar de seus "vícios” (FURTADO, 1979, p. 197).

Como os condicionantes históricos de economias subdesenvolvidas são distintos de economias desenvolvidas, uma mudança tecnológica provoca reações adversas por parte de atores sociais nas primeiras, que prejudicam um ajustamento positivo e suave de uma estrutura social. Enquanto, nas economias ricas seus condicionantes empurram o "sistema econômicosocial" para um equilíbrio de longo prazo ou uma espécie de estado estacionário, Stead State.

\footnotetext{
${ }^{8}$ Nesse tipo de sociedade não existe espaço para apropriação de parcela do excedente para acumulação de capital, todo o excedente é distribuído para consumo.
} 
Nestes países o progresso da ciência assegura a continuidade do progresso técnico e assim, a acumulação de capital tem caminho livre, apesar de poucos entraves institucionais que mudam de maneira mais lenta.

Alguns entraves institucionais implicam na resistência de "formas anacrônicas de distribuição de renda" que se traduzem em insuficiência de demanda efetiva, consumo e investimento. Existem duas possibilidades de resolver esse anacronismo, uma sinalizando os agentes tomadores de decisão em seguir um comportamento "racional", e outra em que as autoridades de política econômica observam inflexibilidades e tomam medidas para eliminar as barreiras entre a realocação do investimento e o consumo em setores e fatores da estrutura econômica (FURTADO, 1964, p. 30).

Do contrário, na economia subdesenvolvida permanece a estrutura social heterogênea em conjunto com os anacronismos econômicos, que geram desequilíbrios estruturais de emprego, preços e comerciais e são fatores determinantes das desigualdades e desequilíbrios relacionados a rigidez de valores culturais arcaicos.

\section{Condicionantes do 'sub'desenvolvimento'}

\subsection{Processo de melhoria tecnológica}

Furtado (1979) sugere que em uma economia capitalista o fenômeno da quase renda originado pelo progresso técnico é temporário, na medida que a realocação de recursos ou fatores de produção dentro da estrutura econômica faz com que os lucros se equalizem entre os setores e o excedente fica, novamente, repartido entre os fatores, como se o benefício fosse distribuído na estrutura interna do sistema econômico.

Cabe destacar que nas economias desenvolvidas, boa parte do progresso técnico é integrante da engrenagem do sistema econômico, existe um conjunto de mercados que demandam e ofertam inovações ou projetos de novas ideias.

Nos países subdesenvolvidos de economia primário-exportadora, o progresso técnico é um condicionante exógeno ${ }^{10}$ para o aumento da produtividade do setor dinâmico da economia, mas também, a importação destas técnicas pode servir como instrumento para ampliar a heterogeneidade estrutural e retroalimentar este subsistema.

\footnotetext{
${ }^{9} \mathrm{O}$ termo 'sub' desenvolvimento com aspas simples tem o objetivo de destacar, que os condicionantes podem levar o desenvolvimento a depender de como são qualificados.

${ }^{10}$ No sentido de que a melhoria técnica e a inovação estão ausentes na economia subdesenvolvida e se processa nas economias centrais.
} 


\subsection{Excedente de mão de obra}

Em uma economia Subdesenvolvida o excedente estrutural de mão de obra é um condicionante endógeno a manutenção do processo de subdesenvolvimento, ou seja, existe uma massa de trabalhadores em setores informais de subsistência. Neste caso, as quase-rendas originárias de aumentos de produtividade por melhoria tecnológica de produção, não são absorvidas entre os fatores de produção disponíveis na estrutura econômica do sistema subdesenvolvido. Para reverter esta condição, é preciso uma forte concorrência na procura por mão de obra, o que esgota o excedente de trabalhadores em setores de subsistência e os benefícios dos ganhos de produtividade passam a ser internalizados. Em economias desenvolvidas, apesar de muitos setores exercerem poder de mercado, o alto nível de investimentos provoca aumentos nas taxas de salários e portanto, absorção dos benefícios do progresso técnico (FURTADO, 1979, p. 198).

Como nas estruturas subdesenvolvidas, os lucros do setor exportador não devem ser inseridos no fluxo interno de renda, o excedente de mão de obra pode ser absorvido sem que ocorra distribuição dessa renda adicional. Furtado (1979, p. 199) sugere que o “subdesenvolvimento é um fenômeno de dominação de natureza cultural e política". Neste sentido, para entender o processo de subdesenvolvimento temos que inserir esta economia no "sistema de divisão internacional do trabalho". O excedente é mantido pela ausência de massa crítica e de baixa participação de uma classe trabalhadora urbana consciente de seu papel, no sistema de produção capitalista. Por isso, uma grande massa de trabalhadores em economia de subsistência ou economia informal ajuda a reproduzir o subdesenvolvimento.

\subsection{Abertura econômica e processo de industrialização}

No caso das economias primário-exportadoras, a abertura econômica era seletiva, apresentando atividades manufatureiras semiartesanais para a produção de bens e serviços de primeira necessidade. E, tendo boa parte dos bens de consumo e de luxo importados, devido ao fato de a lógica da elite dominante tender a não permitir que um grupo capitalista, conteste o domínio econômico e político da classe primário-exportadora. Com o processo de substituição de importações e a industrialização, passa a ocorrer uma mudança econômico-estrutural que redesenha toda a estrutura social de poder com implicações na distribuição política e econômica regional. 
Segundo Furtado (1992, p.9) "a substituição de importações se inicia pelas indústrias mais simples, pouco exigentes em tecnologia e de baixo coeficiente de capital" que ao se desenvolver como um setor mais complexo necessita continuamente ampliar sua capacidade produtiva. Nessa fase se faz necessário expansão da taxa de poupança, e por consequência, estará sempre em busca de recursos externos o que pode implicar em endividamento externo e desequilíbrios. A indústria "poupadora de mão de obra" é condição necessária ao desenvolvimento, mas não suficiente. $O$ processo de industrialização como fator promotor do desenvolvimento se dará mediante redução de heterogeneidade social (FURTADO,1992, p. 9$10)$.

\subsection{Diversificação da estrutura produtiva}

Nas economias subdesenvolvidas, ao superar o modelo primário-exportador, geralmente a diversificação da estrutura produtiva é restrita. Uma das causas fundamentais apontada pelos estruturalistas é a insuficiência de poupança (BIELSCHOWSKY, 2006, p.9). O Investimento Direto Externo (IDE) é visto como uma alternativa importante para superar a insuficiência de poupança, mas pode encontrar dificuldades quando as condições de abertura econômica são ditadas por uma elite obstinada a manter o poder econômico e político. Furtado se mostra favorável ao movimento dos IDE com ressalvas quanto ao fluxo de excedente de renda não retornar na forma de acumulação de capital. ${ }^{11}$

Dentro dessa condição, pode ser inserido a característica primária-exportadora das economias subdesenvolvidas como um condicionante exógeno, em que grande parte dessas economias dotada de recursos naturais abundantes sofreu um tipo de colonização de exploração, o que definiu uma estrutura produtiva de monocultura extensiva ou de extração mineral por longo período. Tal ocorrência fixou um conjunto de valores culturais, dificultando, assim, a diversificação produtiva.

Outros fatores associados podem ser destacados, como o clientelismo arraigado na política de Estado promovendo uma industrialização tardia e dual, e uma falta de diversificação da procura ligada à contínua concentração de renda, o que provoca restrições no tamanho do mercado. Bielschowsky (2006), com base na abordagem do estruturalismo, também apresenta a "falta de instituições adequadas e de capacidade empresarial" como uma característica estrutural das economias Latino Americanas.

\footnotetext{
${ }^{11}$ Leff (1977, 131-2) destaca que a uma forte diferença presente ao comparar os dois planos econômicos na década de 60. No Plano de Campos, o Investimento Direto Externo - IED era visto de maneira incontestável como um fluxo favorável ao desenvolvimento; enquanto, o grupo de Furtado tinha algumas ressalvas e apresentava medidas que regulamentavam os IED.
} 
Para Furtado (1979, p. 273), políticas que resultem com êxito em uma ampla utilização de mão de obra, conduzirão a economia ao desenvolvimento. Nas economias subdesenvolvidas, a força de fatores exógenos como o impulso da expansão da procura externa por produto do setor dinâmico da economia, a política discricionária de Estado e as mudanças estruturais que resultem, por exemplo, em substituição de importações, quase sempre levam a um processo de desenvolvimento.

\section{Considerações finais}

Em síntese, as proposições de Celso Furtado miram de maneira mais objetiva em dois resultados desejáveis, a redução das desigualdades regionais e de renda ao nível civilizado e o crescimento sustentável da produtividade do trabalho. Tais proposições estão assentadas no diagnóstico complexo dos problemas sociais e econômicos enfrentados pelas economias subdesenvolvidas, que apresentam características singulares que dificultam a mobilidade da estrutura econômica e social.

Furtado sugere que o desenvolvimento é como um processo de dissolução de estruturas heterogêneas no caldo do desenvolvimento. De maneira objetiva, o desenvolvimento tende a absorver o subdesenvolvimento no sentido da homogeneização da estrutura econômica, com a ampliação da participação do setor avançado em detrimento do setor atrasado.

Assim, quando se observa em nossas relações sociais a cultura do clientelismo, do patriarcalismo, do machismo, do racismo e do subemprego, isso pode ser apontado como causa e resultado do processo de subdesenvolvimento. Aspectos e valores sociais arcaicos se mantém enraizados em nossa cultura, o que faz do legado de Celso Furtado ser fundamental para o entendimento do processo de subdesenvolvimento, dentro de economias que podem ter um grau de modernização elevado, mas boa parte de sua população não desfruta dos benefícios do progresso.

\section{Referências}

BIELSCHOWSKY, R. Celso Furtado's contributions to structuralism and their relevance today. CEPAL Review. N. 88, (abr), 2006.

BOIANOVSKY, M. Celso Furtado and the structuralist-monetarist debate on economic stabilization in Latin America. History of Political Economy. Vol. 44, N. 2, p. 277-330, 2012. 
BRESSER-PEREIRA, L. C. Method and passion in Celso Furtado. CEPAL Review. N. 84, (dec), 2004.

DELFIM NETTO, A. Planejamento para o desenvolvimento econômico. São Paulo: Livraria Pioneira Editora / Editora da USP, 1966.

FURTADO, C. Formação econômica do Brasil. $4^{\text {a }}$ ed. Rio de Janeiro: Editora Fundo de Cultura, 1961.

Dialética do desenvolvimento. Rio de Janeiro: Editora Fundo de Cultura, 1964.

Nacional, 1979.

. Teoria e Política do Desenvolvimento Econômico. $7^{\text {a }}$ ed., São Paulo: Editora

O subdesenvolvimento revisitado. Economia e Sociedade. Vol. 1, N. 1 (1), p. 519, agosto, 1992.

2005 .

. Formação econômica do Brasil. 32 ed. São Paulo: Companhia Editora Nacional,

LEFF, N. H. Política econômica e desenvolvimento no Brasil. Trad. Roberto Borges Martins. São Paulo: Editora Perspectiva, 1977.

PREBISCH, R. Interpretação do processo de desenvolvimento econômico. Revista Brasileira de Economia. Vol. 5, N. 1, p. 7-117, 1951.

SAMPAIO JR., P. A. Celso Furtado: um economista a serviço da Nação. Prefácio. In: FURTADO, C. Formação econômica do Brasil. $32^{\mathrm{a}}$ ed. São Paulo: Companhia Editora Nacional, 2005.

SZMRECSÁNYI, T. The contributions of Celso Furtado (1920 - 2004) to development economics. Euro. J. History of Economic Thought. 12(4), p. 689-700, 2005. 